\title{
INDUSTRIAL FILTERING IN A NONMETROPOLITAN AREA OF THE SOUTH
}

\author{
Charles A. Campbell*
}

\begin{abstract}
The industrial filtering hypothesis is examined, using employment data for 82 counties in Mississippi. Shift-share analysis is used to explore the underlying question of whether the industrial filtering process adequately provides a general explanation for the growth of nonmetropolitan employment and is an appropriate basis for theories of economic development. Shift calculations are produced for the period of 1969 through 1988 , as well as four subperiods based upon business cycle fluctuations. Two regression models are used in an attempt to statistically test the industrial filtering hypothesis.

The author concludes that the industrial filtering process does not appear to represent a satisfactory explanation for the changes in industrial employment structure within Mississippi based upon the available evidence. The author points out that the evidence is not definitive and suggests that further studies should be based upon firm-specific data.
\end{abstract}

\section{INTRODUCTION}

A common development strategy in nonmetropolitan areas of the South is to seek industrial diversification as a means of providing employment stability. Industrial diversification strategy is an outgrowth of financial portfolio theory (Conroy 1975). Such an approach makes use of the fact that the risk to employment differs, depending upon the specific industry. Diversification reduces the overall risk to employment for any particular time. Increasingly, rural areas are attempting to achieve this increased stability while also achieving higher employment growth and higher wages. Many such areas are pursuing this dual strategy by attempting to diversify into high technology industries where wages are high and where there are relatively fast growth rates of employment.

Recruiting high-wage, high-growth industries may be doomed to failure in rural areas if the concept of industrial filtering is valid. Adherents of industrial filtering maintain that the way in which decentralization of employment (the movement of firms and employment from metropolitan to nonmetropolitan areas) occurs makes it unlikely that truly nonmetropolitan areas will diversify into high wage employment (Bagchi-Sen and Pigozzi 1993). The industrial filtering process is descriptive of a movement of low-wage and low-skill jobs to nonmetropolitan areas, with high-wage jobs remaining concentrated and growing in metropolitan areas.

\footnotetext{
*Associate Professor of Economics, College of Business and Industry, Mississippi State University. The author wishes to gratefully acknowledge the extremely helpful suggestions of the editors and an anonymous referee. Any errors remain the sole responsibility of the author.
} 
This paper uses the shift component of shift-share analysis to explore the underlying question of whether the industrial filtering process adequately provides a general explanation for the growth of nonmetropolitan employment and is an appropriate basis for theories of economic development. It is hypothesized that if the industrial filtering concept is valid, the shift component in industries characterized by high levels of innovation (top-cycle industries) should be positive for metropolitan areas and zero or negative for nonmetropolitan areas. The shift components for more mature, routinized industries should be negative for metropolitan areas and positive for nonmetropolitan areas.

The paper is organized as follows. A review of the industrial filtering process is presented in the second section. Section three explains the organization of the manufacturing industries by area type and product life cycle. In section four, the data is described, data sources are identified and the measure of employment redistribution utilized in this study is specified. Section five presents an initial qualitative analysis of the data which examines estimates of employment change and shift calculations by county group and industrial type. Section six explains the model used to test the hypothesis that industrial filtering was valid in Mississippi over the years 1969 through 1988 and discusses the results of the hypotheses tests. Finally, a summary of findings, limitations, and policy implications is presented in section seven, the conclusion.

\section{THE INDUSTRIAL FILTERING PROCESS}

The industrial filtering process (Thompson 1968 and Erikson 1976), or what has also become known as the theory of product life cycles (Barkley, 1988), suggests that innovative manufacturing and research and development activities associated with new products and industries tend to arise in urban areas and then spread to nonmetropolitan areas as the industry matures (Erikson 1976; Thompson 1968; Thompson 1969; Maskus 1983). This theory is widely accepted and has been used as a basis for various explanations of industrial decentralization and theories of development such as Thompson's "stages of growth theory" (Blair 1991).

The industrial filtering process assumes that firms are profit maximizers and that profit is maximized in the early and innovative stages of product development by locating in urban areas. In the initial stage of a product's life cycle, production levels tend to be small scale. The economic costs of congestion and high rents at the urban center are more than offset by the availability of highly skilled labor, business services, suppliers, customer bases and other factors which give rise to 
great flexibility in the development and early production stages. Profit maximization is thus more likely to occur in metropolitan areas in these early stages.

As the industry or firm matures, production becomes more routine and less reliant upon highly technical skills and flexibility. Production also tends to move to a larger scale. At some point in this process the congestion and high rents at the urban center become significant problems. High-wage labor and the infrastructure unique to metropolitan areas become less and less necessary. Relocation to nonmetropolitan areas in such a stage tends to reduce costs and therefore maximize profits. The implications of such filtering from metropolitan areas to nonmetropolitan areas is important not only to understanding the dynamics of industrial location, but also to the establishment of sound economic development policies for nonmetropolitan areas.

The analysis which follows examines whether employment shifts in Mississippi during the 1970s and 1980s support the industrial filtering theory. Mississippi has a substantial proportion of employment in manufacturing (an estimated 26 percent of total nonagricultural employment in 1993) and is a state composed primarily of nonmetropolitan areas. During the 1970 s and 1980 s there was substantial growth in manufacturing industries within the state. While Mississippi is certainly not representative of all nonmetropolitan states or regions, it may serve as partial evidence for nonmetropolitan employment growth patterns. The state's nonmetropolitan areas are particularly noted for low-skill, nonunion, low-wage labor, which have been used by development groups within the state to lure manufacturers to these nonmetropolitan areas. Thus, Mississippi certainly fits the description of the characteristics that profit-maximizing firms in mature industries should seek. The state also currently contains seven metropolitan counties that comprise or are part of Metropolitan Statistical Areas (MSA's) from which at least some of the growth of employment should decentralize to the nonmetropolitan areas. The emphasis here is upon decentralization within the state rather than interregional decentralization. If decentralization does not occur in accordance with the theory within the state, it does not mean that interregional decentralization does not occur; however, it does suggest that such a theory may not be an adequate explanation for regional growth. Such a finding would simply suggest that industrial filtering may be too simplistic to serve as a major explanation. In such a case, if the theory is to be descriptive, it must take into account regional differences in the nature of both metropolitan and nonmetropolitan areas as well as the metropolitan to nonmetropolitan movements. 


\section{ORGANIZATION OF MANUFACTURING INDUSTRIES AND AREAS}

Manufacturing sectors in this study have been grouped into three general categories (Gilmer and Pulsipher 1986; Maskus 1983; Huffbauer and Chilas 1974). These include: 1) resource-based industries, 2) industries at the top of the product cycle, and 3) industries at the bottom of the product cycle. Resourcebased industries are those industries which directly use or convert natural resources or farm products. Such industries tend to exhibit a relatively low level of innovation with obvious exceptions for specific firms or four-digit Standard Industrial Classifications (SIC) codes (Gilmer and Pulsipher 1986). Top-cycle industries are characterized by a high degree of product innovation, a relatively high degree of new operations and products, and relatively high wages. Bottom-cycle industries are characterized by low levels of innovation, mature and routinized operations, and relatively low wages.

Norton and Rees (1979) examined the number of significant innovations per dollar of shipments from 1961 to 1976 . These rankings were used by Gilmer and Pulsipher, along with information unique to the Southeast for particular industries to create a grouping of industries according to product cycle. Table 1 reproduces Gilmer and Pulsipher's classifications along with Norton and Rees' ranking according to innovations (Gilmer and Pulsipher 1986, p. 63.) Since the data used in

\section{TABLE 1}

Classification of Two-Digit SIC Code Industries and Rankings in Achievement of Significant Innovation

\begin{tabular}{lrlrlr}
\hline \hline & & \multicolumn{2}{c}{ Top-of-Product Cycle } & & \\
Resource-Based Industry & & \multicolumn{2}{c}{ Industry } & & \multicolumn{2}{c}{ Bottom-of-Cycle Industry } \\
\hline Industry & Rank & Industry & Rank & Industry & Rank \\
Food & 16 & Chemicals & 6 & Textiles & 12 \\
Tobacco & NR & Rubber \& plastics & 3 & Apparel & 14 \\
Lumber & 9 & Electrical machinery & 5 & Furniture & 10 \\
Paper & 13 & Other machinery & 4 & Printing \& publishing & NR \\
Petroleum & 15 & Instruments & 1 & Leather & NR \\
Stone, clay \& glass & 2 & & & Primary metals & 8 \\
& & & & Fabricated metals & 7 \\
& & & & Transport. equipment & 11 \\
& & & Misc. manufacturing & NR \\
\hline
\end{tabular}

Note: NR means not ranked

Source: Gilmer and Pulsipher 1986, page 63. 
this study span the period 1969 to 1988 this ranking would seem to be valid for the current study.

Five of the six most innovative industries are grouped into the Top-of-Cycle Industry group. The Bottom-of-Cycle group includes all of the remaining industries except those which are clearly resource-based. With the exception of the stone, clay and glass sector, all resource-based industries could be grouped as bottom-cycle industries. However, since resource-based industries are more likely to locate near the source of the resource being processed, they are considered a separate group, and stone, clay and glass are not moved to the top-cycle category.

Employment data based upon these product cycle categories are aggregated into three basic area types. The first group, comprised of metropolitan counties, is defined as those seven counties out of the total 82 counties which are at least partially included in any MSA as of 1980 . These counties include DeSoto (part of the Memphis MSA), Hinds, Madison, and Rankin (the Jackson MSA), Hancock and Harrison (the Biloxi-Gulfport MSA) and Jackson (the Pascagoula-Moss Point MSA). The second area group defined includes those 16 counties adjacent to counties containing at least part of an MSA. These include the counties of Marshall, Tate, Tunica, Yazoo, Holmes, Attala, Leake, Scott, Smith, Simpson, Copiah, Claiborne, Warren, Pearl River, Stone, and George. Finally, nonmetropolitan, nonadjacent areas are defined as those remaining 59 counties which are neither metropolitan nor adjacent to a metropolitan area.

\section{DATA SOURCES AND THE MEASURE OF EMPLOYMENT REDISTRIBUTION}

Employment estimates used in this analysis are at the two-digit level of Standard Industrial Classification (SIC) codes from unpublished Bureau of Economic Analysis (BEA) data. These data were obtained from the Tennessee Valley Authority for the years 1969 through 1988 but are subject to confidentiality restrictions. The data shown in all tables has been aggregated to the twodigit level and by county groups to eliminate disclosure problems. Such aggregation does result in a loss of precision but the general groups do retain a good deal of cohesion by product life cycle. More detailed data on a county level was not available. Regressions are based upon county specific data but only overall results are reported to retain confidentiality. The tobacco manufacturing sector and the ordinance sector have not been included in the analysis, since employment in tobacco is zero in all years and the employment in ordinance is zero in all years after 1972. 
The primary variable used to investigate this phenomenon is the shift component of shift-share analysis. Cyclical fluctuations do influence the elements of shift-share analysis (Campbell 1989). For this reason an attempt was made to use similar stages in the state's business cycle for analysis. Since manufacturing industries are the focus of this analysis, fluctuations in Mississippi manufacturing employment have been utilized to choose the peak and trough periods. Both peak and trough periods were used to investigate the sensitivity of the findings to differences in the business cycle. The analysis periods included are two periods of peak-to-peak years (1973 to 1978 and 1978 to 1988), two periods of trough-totrough years (1969 to 1975 and 1975 to 1982), and the entire 1969-to-1988 period.

The data is limited to Mississippi, which also limits the degree to which one should generalize from these results. In the spirit of Erikson (1976), this is used as simply one test of the filtering down process.

Following Barkley (1988), the shift component of shift-share analysis is used as the measure of employment redistribution. The choice of the shift component provides a relative measure of employment change. Moreover, the calculation of the shift component has been tailored to measure redistribution of manufacturing employment within the state, as opposed to the normal measure, where redistribution of total employment is measured relative to the nation. This allows for a measure which is relative to Mississippi manufacturing employment and is more useful for this study than an absolute measure such as the net change in employment.

Following Barkley's (1988) nomenclature with slight modifications, the shift component is calculated as follows:

$$
S_{i j}=E_{i j}^{t}-E^{t-1} i j\left(M S_{i}^{t} / M S^{t-1}\right)
$$

and

$$
S_{j}=\operatorname{Sum} S_{i j}
$$

where:

$$
\begin{aligned}
& S_{i j}=\text { employment shift for two-digit SIC industry } i, \text { county } j ; \\
& S_{j}=\text { employment shift for county } j \\
& E_{i j}=\text { industry i employment in county } j \\
& M S_{i}=\text { State employment in industry } i ; \\
& t=\text { end year of the period, } t-1 \text { is first year of the period. }
\end{aligned}
$$

This shift component then measures the difference between the actual employment level in the county for a specific industry and the level that would have occurred had the industry attained the same growth rate for both the state as a whole and for the county. A positive shift component indicates that the con- 
centration of the county's share of employment in the industry has increased, reflecting a relative shift of employment into the county. Likewise a negative shift indicates a relative shift out of the county. These components are aggregated across counties for each specific area group and across industries within these county groups by product cycle group.

Obviously, since the state is used as the base, the shift components for all areas in a given year must sum to zero.

\section{ESTIMATES OF EMPLOYMENT CHANGE BY COUNTY GROUP AND INDUSTRY}

Overall Employment Growth Patterns. Table 2 displays manufacturing employment for the end periods under examination and the overall growth rates for each of the area types and product cycle groups. For the overall period, total manufacturing employment grew by 56,712 or 30.94 percent. The most striking growth rate occurred in top-cycle industries in metropolitan counties, with the increase of 7847 representing a 138 percent growth between 1969 and 1988 . The lowest growth rate occurred in Metropolitan resource-based industries (11 percent). As a group, the top-cycle industries showed the largest growth in percentage terms ( 67 percent or 21,590 jobs). Bottom-cycle industries lagged behind in terms of growth rates ( 27 percent) but led in absolute employment growth $(25,074$ jobs). Resource-based industries grew the slowest in both percentage and absolute terms (17.8 percent or 10,048 jobs.)

With respect to county groups, the largest percentage employment growth was concentrated in metropolitan areas (40.51 percent or 15,906 jobs), but as expected, due to their sheer numbers, the 59 nonadjacent areas led in absolute employment growth (36,310, or 30 percent). Surprisingly, those counties adjacent to metropolitan areas showed the lowest percentage gains in employment with only about 19 percent growth.

The overall picture is thus one of two important influences. There is substantial growth in top-cycle industries, but bottom-cycle industries remain important because of their large base. Secondly, while metropolitan areas are growing rapidly, there is impressive growth in nonadjacent, truly nonmetropolitan, counties even in top-cycle industries.

Results of Shift Calculations. Table 3 shows a summary of the shift calculations aggregated by industry, product cycle and county groups for each of the subperiods and for 1969 through 1988. (More detailed shift calculations are available from the author upon request.) 
TABLE 2

Employment by Period, Area, and Product Cycle

\begin{tabular}{|c|c|c|c|c|c|c|c|c|}
\hline \multirow[b]{2}{*}{ Employment by year } & \multirow[b]{2}{*}{ Trough } & \multirow[b]{2}{*}{ Trough } & \multirow[b]{2}{*}{ Trough } & \multirow[b]{2}{*}{ Peak } & \multirow[b]{2}{*}{ Peak } & \multicolumn{3}{|c|}{$\%$} \\
\hline & & & & & & Peak & Growth & Growth \\
\hline Year & 1969 & 1975 & 1982 & 1973 & 1978 & 1988 & $1969-88$ & $1969-88$ \\
\hline Nonadjacent Bottom-cycle & 63599 & 63351 & 64736 & 74978 & 74164 & 80505 & 26.58 & 16906 \\
\hline Adjacent Bottom-cycle & 9431 & 10700 & 10751 & 11526 & 12017 & 10861 & 15.16 & 1430 \\
\hline Metropolitan Bottom-cycle & 21498 & 33409 & 27961 & 30397 & 34928 & 28236 & 31.34 & 6738 \\
\hline Total Bottom-cycle & 94528 & 107460 & 103448 & 116901 & 121109 & 119602 & 26.53 & 25074 \\
\hline Nonadjacent Top-cycle & 20443 & 25796 & 28584 & 28048 & 34780 & 33509 & 63.91 & 13066 \\
\hline Adjacent Top-cycle & 6231 & 5938 & 5901 & 8508 & 7609 & 6908 & 10.87 & 677 \\
\hline Metropolitan Top-cycle & 5688 & 8967 & 10591 & 8659 & 10036 & 13535 & 137.96 & 7847 \\
\hline Total Top-cycle & 32362 & 40701 & 45076 & 45215 & 52425 & 53952 & 66.71 & 21590 \\
\hline Nonadjacent Resource-based & 35889 & 33972 & 34388 & 37690 & 38781 & 42227 & 17.66 & 6338 \\
\hline Adjacent Resource-based & 8434 & 8374 & 9186 & 9264 & 10522 & 10823 & 28.33 & 2389 \\
\hline Metropolitan Resource-based & 12081 & 12505 & 12612 & 12825 & 14226 & 13402 & 10.93 & 1321 \\
\hline Total Resource-based & 56404 & 54851 & 56186 & 59779 & 63529 & 66452 & 17.81 & 10048 \\
\hline Total Nonadjacent & 119931 & 123119 & 127708 & 140716 & 147725 & 156241 & 30.28 & 36310 \\
\hline Total Adjacent & 24096 & 25012 & 25838 & 29298 & 30148 & 28592 & 18.66 & 4496 \\
\hline Total Metropolitan & 39267 & 54881 & 51164 & 51881 & 59190 & 55173 & 40.51 & 15906 \\
\hline \multicolumn{9}{|l|}{ Total Employment } \\
\hline in Manufacturing & 183294 & 203012 & 204710 & 221895 & 237063 & 240006 & 30.94 & 56712 \\
\hline
\end{tabular}

Source: BEA unpublished data (1992)

TABLE 3

Summary of Shift Calculations by Period, Area, and Product Type

\begin{tabular}{lrrrrr}
\hline Period & $1969-75$ & $1975-82$ & $1973-88$ & $1978-88$ & $1969-88$ \\
\hline Top-cycle Nonadjacent & 3154 & 2572 & 4815 & -1703 & 6741 \\
Resource-based Nonadjacent & -5778 & 132 & -1485 & 2965 & -4766 \\
Bottom-cycle Nonadjacent & -7090 & 855 & -5939 & 5420 & -2772 \\
Total Nonadjacent & -9714 & 3559 & -2610 & 6682 & -797 \\
Top-cycle Metropolitan & 2667 & 1549 & 785 & 3374 & 6087 \\
Resource-based Metropolitan & -876 & 2 & 524 & -1001 & -2417 \\
Bottom-cycle Metropolitan & 9598 & -5727 & 2453 & -7126 & 86 \\
Total Metropolitan & 11390 & -4176 & 3763 & -4752 & 3757 \\
Top-cycle Adjacent & -963 & -87 & -1481 & -795 & -1251 \\
Resource-based Adjacent & -967 & 742 & 625 & 170 & -221 \\
Bottom-cycle Adjacent & 254 & -38 & -297 & -1305 & -1488 \\
Total Adjacent & -1676 & 617 & -1153 & -1930 & -2959 \\
Total Top-cycle & 4858 & 4035 & 4119 & 876 & 11577 \\
Total Resource-based & -7621 & 876 & -336 & 2134 & -7404 \\
Total Bottom-cycle & 2763 & -4911 & -3783 & -3010 & -4173 \\
Total Nonadjacent & -9714 & 3559 & -2610 & 6682 & -797 \\
Total Adjacent & -1676 & 617 & -1153 & -1930 & -2959 \\
Total Metropolitan & 11390 & -4176 & 3763 & -4752 & 3757 \\
\hline
\end{tabular}


Between 1969 and 1988 there was a shift of employment from nonmetropolitan counties into metropolitan areas. This same general pattern appears in the 1969-to-1975 and 1973-to-1978 subperiods as well. In the second troughto-trough period (1975 to 1982), however, the pattern is reversed, with employment shifting out of the metropolitan areas into both adjacent and nonadjacent metropolitan areas. Finally, the 1978-to-1988 period (peak to peak) shows employment shifting out of both metropolitan and adjacent counties into nonadjacent counties. Thus the short-term fluctuations do not appear to follow a particular pattern with respect to business cycle fluctuations.

With respect to the aggregated area groups, the 1969-to-1988 pattern of employment shifts into top-cycle industries does hold for each of the subperiods. Except for the 1969-to-1975 period, the bulk of such shifts generally comes at the expense of bottom-cycle industries, alternating between positive and negative shifts in the resource-based industries. Moreover, top-cycle industries in metropolitan counties experienced positive shifts both for the overall 1969 to 1988 period and in each of the subperiods. Top-cycle industries in nonadjacent counties also appeared to gain from the shifts during the overall 1969 to 1988 period and in all but one of the subperiods. Contrary to a priori assumptions, however, counties adjacent to metropolitan areas experienced negative shifts of employment in top-cycle industries in the overall period and in each of the subperiods.

Results during the subperiods were mixed for both resource-based industries and bottom-cycle industries in metropolitan areas. There were negative shifts for the overall period for the resource-based industries and a very slight positive shift for the bottom-cycle industries, but the results differed widely, depending upon the particular subperiod examined.

Shift components for adjacent counties were negative during the overall period for each of the product cycle groups. For the resource-based industries in adjacent counties, positive shifts during three of the subperiods were overpowered by the negative shift in 1969 to 1975 . For the bottom-cycle industries, there were large negative shifts in all but the first subperiod.

In general, the results tend to support the industrial filtering hypothesis to the extent that shift components for top-cycle industries in metropolitan areas were positive in each subperiod and of the overall period. Contrary to the hypothesized results, however, nonadjacent counties also tended to experience positive shift components in top-cycle industries. The industries contributing to the positive shifts in top-cycle industries for metropolitan areas appeared to be broad based and relatively constant, with each of the individual top-cycle industries showing positive shifts overall. The only negative shifts observed occurred in two sub- 
periods for the rubber and miscellaneous plastics sector and in one subperiod for the instruments sector.

On the other hand, the positive shifts in top-cycle industries for nonadjacent counties were limited to the nonelectrical machinery, electrical and electronic equipment, and rubber and plastics sectors. Moreover, each of these sectors experienced some negative shifts in the subperiods.

It should be noted that with respect to particular industries and county groups, the largest positive shift calculated for nonadjacent counties was for the furniture and fixtures sector (10,079 for 1969-1988) and the largest negative shift calculated for such counties was in the apparel sector $(-12,924$ for 1969-1988) both of which are bottom-cycle industries.

For adjacent counties, the largest negative shift was in the nonelectrical machinery sector (-882 for 1969-1988), and the largest positive shift was in the rubber and plastics sector (849 for 1969-1988). Both are classified as top-cycle industries.

\section{REGRESSION ANALYSIS}

Regression analysis was performed in order to test the null hypothesis that county type (metropolitan, adjacent, or nonadjacent) or product cycle group (topcycle, bottom-cycle, or resource-based industries) were not significant in determining the sign and level of relative shift components. The data set, consisting of data for each of the 82 counties in each of the four subperiods for each of the product cycle types, totaled 984 observations. For each observation the dependent variable was the calculated shift component for a specific county for a specific product cycle group in one of the four subperiods relative to total manufacturing employment at the beginning of the subperiod. Independent variables included dummy variables indicating the county location type, dummy variables indicating the product cycle group, dummy variables indicating which of the four subperiods was being used, and the percent of total employment represented by manufacturing employment at the beginning of the subperiod. The model estimated was (with subscripts eliminated):

$$
\begin{array}{ll}
\text { relshif }= & \mathrm{b}_{1} * \text { top }+\mathrm{b}_{2} * \mathrm{bot}+\mathrm{b}_{3} * \text { met }+\mathrm{b}_{4} * \mathrm{adj}_{\mathrm{j}}+\mathrm{b}_{5} * \mathrm{p} 1+\mathrm{b}_{6} * \mathrm{p} 2+ \\
& \mathrm{b}_{7} * \mathrm{p} 3+\mathrm{b}_{8} * \mathrm{pctmfg}, \text { where }
\end{array}
$$




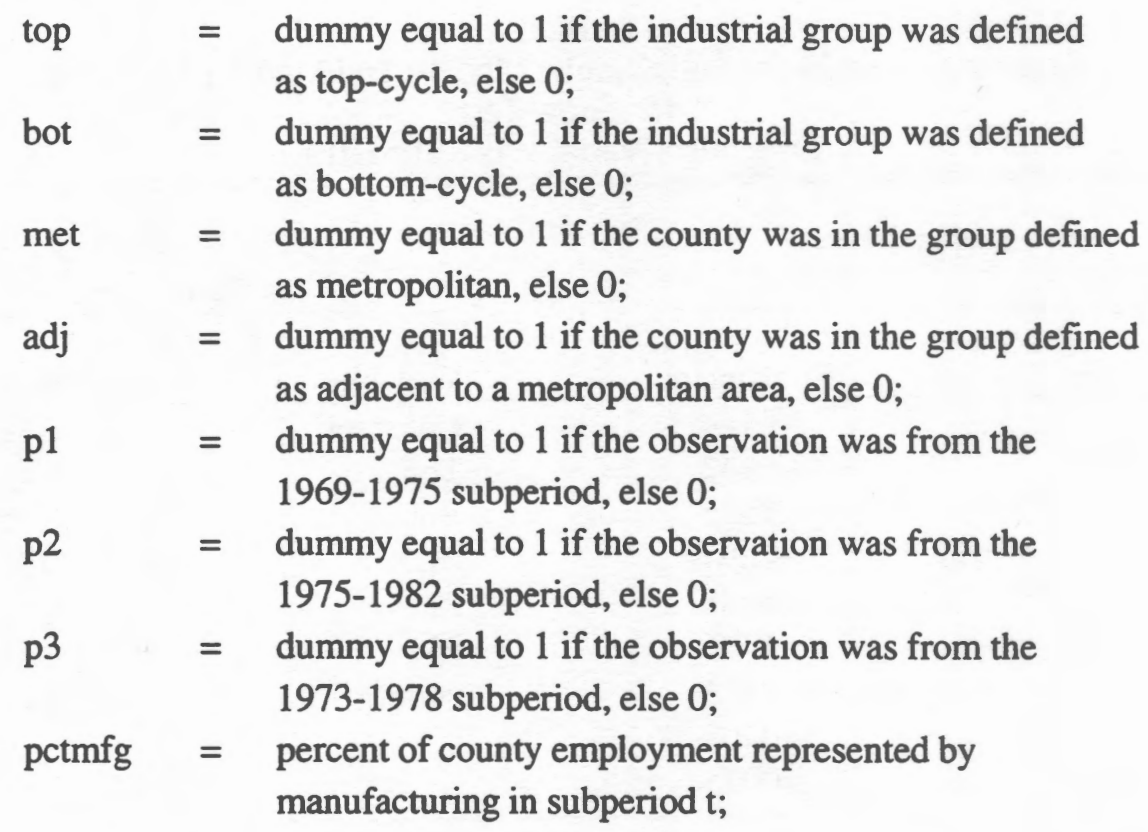

Results of the regression are shown in Table 4. While the F-statistic for the regression is significant at the 10 percent level, the regression provides very little explanatory power, having an adjusted R-squared of only .024 . Only one variable (the dummy for metropolitan areas) was significant at the 10 percent level. This result did lend partial support for rejection of the null hypothesis and was consistent with the a priori assumption that metropolitan areas would be found to have positive shifts in employment relative to their total manufacturing base. The results were not, however, supportive of the underlying assumptions. The industrial filtering hypothesis would suggest that if an observation was from a topcycle industry in a metropolitan area, it should have a significantly higher probability of a positive relative shift component than if it were merely from a metropolitan area. Yet the "top" variable was both negative and insignificant.

Because there might be differences in slopes and intercepts based upon the county groups involved, the regression was modified and the Chow test was performed to test the hypothesis that all slopes and intercepts were the same. The regression then became:

$$
\text { relshif }=\mathrm{f}(\text { top, bot, } \mathrm{p} 1, \mathrm{p} 2, \mathrm{p} 3, \mathrm{pctmfg})
$$

and was estimated for the entire sample (Table 4) and separately for the observations making up the metropolitan adjacent, and nonadjacent portions of the sample (Table 5). The Chow test was then calculated, demonstrating that the slopes and intercepts of the individual groups of observations were significantly 
TABLE 4

Regression Results for Full Sample: Model 1 and Model 1 Modified for Chow Test

(Dependent Variable is RELSHIF)

\begin{tabular}{|c|c|c|c|}
\hline \multicolumn{2}{|c|}{ Model 1} & \multicolumn{2}{|c|}{$\begin{array}{l}\text { Model } 1 \text { Modified } \\
\text { for Chow Test }\end{array}$} \\
\hline Variable & Coefficient & Variable & Coefficient \\
\hline Constant & -.0144 & Constant & .0838 \\
\hline Top & -.0143 & Top & -.0143 \\
\hline Bot & .1575 & Bot & .1575 \\
\hline Met & $.7894 *$ & P1 & .1754 \\
\hline Adj & -.0488 & P2 & .0129 \\
\hline P1 & .1776 & P3 & -.0441 \\
\hline P2 & .0123 & Pctmfg & -.0045 \\
\hline P3 & -.0408 & & \\
\hline Pctmfg & -.0028 & & \\
\hline $\mathrm{N}$ & 984 & $\mathrm{~N}$ & 984 \\
\hline $\bar{R}^{2}$ & .024 & $\bar{R}^{2}$ & .001 \\
\hline F & $3.99 *$ & F & 1.22 \\
\hline
\end{tabular}

*Denotes significance at 10 percent level.

TABLE 5

Regression Results for Model 1

by County Type

(Dependent Variable is RELSHIF)

\begin{tabular}{lccc}
\hline \hline Variable & Metropolitan & Adjacent & Nonadjacent \\
\hline Constant & -.1137 & -.1277 & $.0565^{*}$ \\
Top & .0383 & $-.0870 *$ & -.0008 \\
Bot & $2.2412 *$ & -.0462 & $-.0344 *$ \\
P1 & $2.4303 *$ & .0274 & $-.0374 *$ \\
P2 & .2019 & .0415 & -.0209 \\
P3 & .0018 & -.0467 & $-.0375 *$ \\
Pctmfg & -.0253 & $.0060^{*}$ & -.0007 \\
\hline $\mathrm{N}$ & 84 & 192 & 708 \\
$\bar{R}^{2}$ & .026 & .023 & .006 \\
$\mathrm{~F}$ & 1.38 & $1.76 *$ & 1.74 \\
\hline
\end{tabular}

*Denotes significance at 10 percent level. 
different from the overall results. Subsequently, the observations were partitioned into metropolitan and nonmetropolitan (both adjacent and nonadjacent) groups and the same test was performed on the nonmetropolitan group relative to the two individual groups that comprised it. Each subgroup was found to be significantly distinct with respect to slopes and intercepts. In no case did the results show more than a very low level of explanatory power, and the F-statistics for the individual regressions were significant only for the adjacent county model.

The F-statistic for the metropolitan regression was not significant at the 10 percent level and only two variables (Bot and $\mathrm{p} 1$ ) were significant at the 10 percent level. The adjusted $R$-square remained very low at .026 .

The model for adjacent counties resulted in an F-statistic which was significant at the 10 percent level, but an adjusted R-squared of only .023. Coefficients for the top-cycle dummy and the percent of employment in manufacturing were significant, indicating that for adjacent counties, top-cycle industries tended to lead to lower shifts relative to total employment, which seems roughly consistent with the results presented in section IV. For adjacent counties, higher percentages of employment in manufacturing lead to higher relative shifts.

The model for nonadjacent counties resulted in three coefficients that were significant at the 10 percent level (Bot, p1, and p3) all of which had negative coefficients. However, the F-statistic indicated a regression that was not significant at the 10 percent level and that had an adjusted R-squared of only .006 .

An alternative model was also constructed which aggregated the shifts for all industries into a single variable for each county in each period. That model was (with subscripts eliminated)

$$
\begin{aligned}
& \text { Relshif }=b_{0}+b_{1} * \text { toppct }+b_{2} * b_{\text {botpct }}+b_{3} * \text { respct }+b_{4} * \text { met }+ \\
& \text { b5*adj + b6 }{ }^{*} \text { p } 1+b_{7} * \mathrm{p} 2+b_{8} * \mathrm{p} 3 \text {, where } \\
& \text { relshif }=\text { the calculated shift component in each period for each } \\
& \text { county divided by total employment for the county at the } \\
& \text { beginning of the period; } \\
& \text { toppct = the level of top-cycle employment in each county at the } \\
& \text { beginning of the period as a percent of total employment } \\
& \text { in the county at the beginning of the period; } \\
& \text { botpct = the level of bottom-cycle employment in each county at the } \\
& \text { beginning of the period as a percent of total employment } \\
& \text { in the county at the beginning of the period; } \\
& \text { respct }=\text { the level of resource-based employment in each county } \\
& \text { at the beginning of the period as a percent of total } \\
& \text { employment in the county at the beginning of the period; }
\end{aligned}
$$




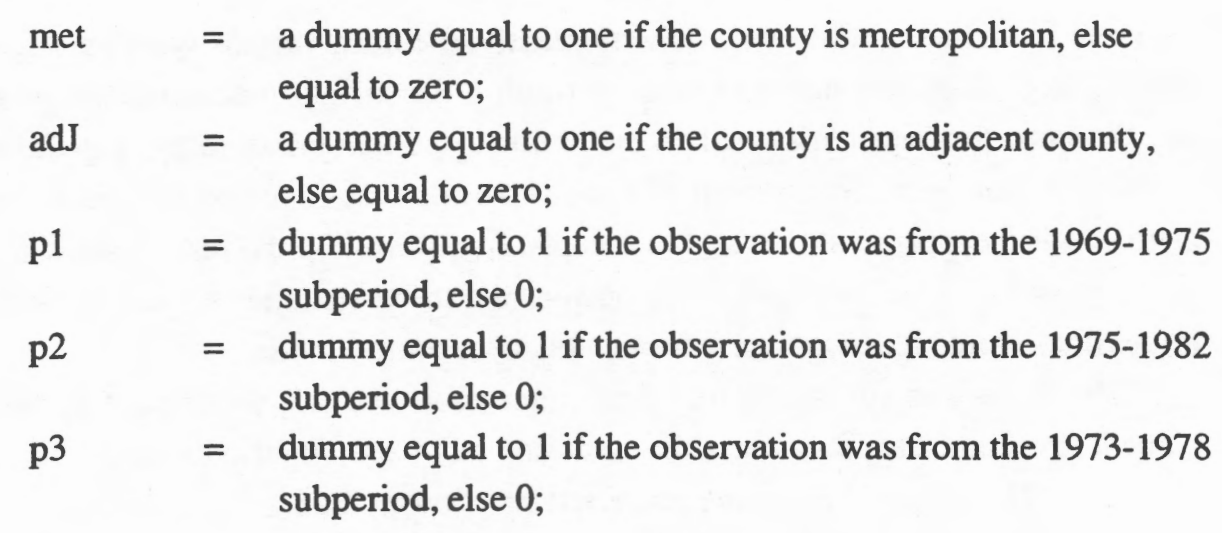

The result of the alternative model (Table 6) was an adjusted $R$ squared of .107 and an F-statistic which was significant at the 1 percent level. Even though this is much more satisfactory than the first set of models, the level of explanatory power is still very low and only one coefficient was significant at the 10 percent level. This was the coefficient for the metropolitan county dummy which indicated that being a metropolitan county increased the amount of shift relative to total employment, regardless of the percent of total employment in top-cycle, bottom-cycle, or resource-based manufacturing or the period being used.

Both basic models provide very limited support for the industrial filtering hypothesis. Metropolitan areas do experience more in positive shifts relative to their total employment base than nonmetropolitan areas, but there is no explana-

TABLE 6

Regression Results for Model 2: All Counties (Dependent Variable is RELSHIF)

\begin{tabular}{lc}
\hline \hline Variable & Coefficient \\
\hline Constant & .0195 \\
Toppct & -.0017 \\
Botpct & -.0002 \\
Respct & -.0008 \\
Met & $.1335 *$ \\
Adj & -.0149 \\
P1 & .0127 \\
P2 & -.0069 \\
P3 & -.0185 \\
N & 328 \\
$\bar{R} 2$ & .107 \\
F & $5.90 *$ \\
\hline
\end{tabular}

*Denotes significance at 10 percent level. 
tion for the sources or reasons for these positive shifts. However, there are two likely possibilities. First, it is possible that the reasons for shifting employment are much more complex than indicated by the industrial filtering model. Second, and equally likely, is that the divisions of manufacturing employment are not fine enough.

\section{CONCLUSION}

It is clear that for Mississippi the bulk of relative shifts of employment into nonadjacent areas over the 1969-to-1988 period is due to growth that is concentrated in several top-cycle and bottom-cycle industries, particularly furniture and fixtures (bottom-cycle), electrical and electronic equipment (top-cycle), nonelectrical machinery (top-cycle) and rubber and plastics industries (top-cycle). This gives the indication that nonmetropolitan developers might indeed act appropriately in courting top-cycle, innovative industries as well as fast-growing bottom-cycle industries in their efforts to diversify. However, the results do also lend some support to the hypothesis that metropolitan areas are serving as growth centers if not clearly incubators for innovative industries.

Developers in nonmetropolitan areas should still be cautious in their efforts to diversify. It could be argued that the particular plants representing, for example, the machinery industries, are in fact plants with routinized production, thus fitting the industrial filtering hypothesis quite well. If this is the case, attracting such plants from innovative industries may raise wages and promote employment stability, but this does not mean such areas are attracting high technology firms or employment.

The most troubling result in the current study concerns the counties adjacent to metropolitan areas, which one would expect to be the first beneficiaries of the filtering process. The negative shift components in such counties may be the result of suburbanization and their specialization as residential areas (or bedroom communities), rather than manufacturing centers.

Although the industrial filtering process has a great deal of intuitive appeal, it does not appear to represent a satisfactory explanation for the changes in industrial employment structure within Mississippi, based upon the available evidence. Moreover, nonmetropolitan Mississippi is likely to be rather typical of many southern rural areas with significant pools of unskilled or lower skilled workers. For such areas, the industrial filtering hypothesis or the product lifecycles theory does not yet appear to represent a complete or satisfactory theory on which to base development efforts or policy. 
This study, unfortunately, does not clearly support or reject the industrial filtering hypothesis. It does give some indication that employment is being shifted into metropolitan areas, but the extent to which this supports industrial filtering is quite unclear. There is evidence that nonmetropolitan counties may also gain substantial shifts in employment even in some innovative industries.

There are certainly limitations to the study. It is limited in examining only Mississippi counties and in examining only shifts within the state. It is also limited in that the product cycle categories are very broad. In addition, it is possible that with more refined data, preferably firm-specific data, that a better understanding might be achieved. Finally, the study is based upon employment data and does not include any wage or income data. Thus, this study is merely a first step in examining the industrial filtering hypothesis.

Probably the most important result of the study is one concerned with further research in the area. Further research into the industrial filtering hypothesis should involve examination of firm-specific information based upon innovations in the firm rather than the industry. In addition, linkages between metropolitan and nonmetropolitan firms and operations should be examined. In other words, it appears that a thorough examination of the industrial filtering hypothesis requires micro data and aggregated data may simply not provide enough detail to address the issue adequately.

\section{REFERENCES}

Bagchi-Sen, S., and B.W. Pigozzi. "Occupational and Industrial Diversification in the United States: Implications of the New Spatial Division of Labor." Professional Geographer 45-1 (1993): 44-54.

Barkley, D.L. "The Decentralization of High-Technology Manufacturing to Nonmetropolitan Areas." Growth and Change 19-1 (1988): 13-30.

Blair, J.P. Urban and Regional Economics. Homewood, Ill.:Richard D. Irwin, 1991.

Campbell, Charles A. "Differential Cyclic Employment Response in a Subregion." The Review of Regional Studies 19-3 (1989): 31-36.

Conroy, Michael E. "The Concept and Measurement of Regional Industrial Diversification." Southern Economic Journal 41 (1975): 492-505.

Erikson, R.A. "The Filtering-Down Process: Industrial Location in a Nonmetropolitan Area." Professional Geographer 26 (1976): 254-60.

Gilmer, R.W., and A.G. Pulsipher. "Cyclical and Structural Change in Southern Manufacturing: Recent Evidence from the Tennessee Valley": Note. Growth and Change 17-4 (1986): 61-69. 
Hufbauer, G.G., and J.G. Chilas. "Specialization by Industrial Countries: Extent and Consequences." In The International Division of Labor: Problems and Prospects, ed. H.G. Giersch. Tubingen, Germany:J.C.B. Mohr, 1974.

Maskus, K.E. The Changing Structure of Comparative Advantage in American Manufacturing. Ann Arbor: UMI Press, 1983.

Norton, R.D., and J. Rees. "The Product Cycle and the Spatial Decentralization of U.S. Manufacturing." Regional Studies 13 (1979): 141-51.

Thompson, W.R. "Internal and External Factors in the Development of Urban Economics." In Issues in Urban Economics, ed. H.S. Perloff and L. Wingo. Baltimore: The Johns Hopkins Press, 1968.

Thompson, W.R. "The Economic Base of Urban Problems." In Contemporary Economic Issues, ed. Neil W. Chamberlain. Homewood, Ill:R.D. Irwin, 1969. 